\title{
Indications for extrahepatic bile duct resection due to perineural invasion in patients with gallbladder cancer
}

Suguru Maruyama, Hiromichi Kawaida, Naohiro Hosomura, Hidetake Amemiya, Ryo Saito, Hiroki Shimizu, Shinji Furuya, Hidenori Akaike, Yoshihiko Kawaguchi, Makoto Sudo, Shingo Inoue, Hiroshi Kono and Daisuke Ichikawa*

\begin{abstract}
Background: The indications for extrahepatic bile duct (EHBD) resection remain a major controversy in the surgical management of patients with gallbladder cancer. On the other hand, perineural invasion (PNI) was reported as an important factor in patients with gallbladder cancer because gallbladder cancer cells frequently spread to the tissues surrounding the EHBD via perineural routes. We assessed the correlation of PNI with clinicopathological factors in patients with gallbladder cancer to elucidate EHBD resection indications specifically in patients with PNI.

Methods: This retrospective study assessed the PNI status of 50 patients with gallbladder cancer who underwent curative resection and examined the correlation between the presence of PNI and clinicopathological factors.

Results: Thirteen patients (26\%) were PNI positive. PNI was significantly correlated with male sex, proximal-type tumor, lymphatic and vascular invasion, and advanced T stage. Multivariate analysis found that PNI positivity ( $p<$ $0.001)$, lymphatic invasion $(p=0.007)$, and nodal stage $(p<0.001)$ were independent prognostic factors. PNI was never observed in patients with stage T1 cancer. Conversely, PNI was detected rarely in distal-type tumors, all of whom developed various types of recurrences.
\end{abstract}

Conclusions: These results clearly demonstrated the prognostic impact of PNI in patients with gallbladder cancer. We suggest that EHBD resection in combination with cholecystectomy may not be useful for distal-type tumors from a perspective of PNI.

Keywords: Gallbladder cancer, Perineural invasion, Extrahepatic bile duct resection

\section{Introduction}

Gallbladder cancer is recognized as one of the most aggressive tumors, with a dismal prognosis [1]; even after curative surgery, the prognosis ranges from 17 to $45 \%$ [2]. In addition to aggressive nature of cancer, the anatomic features of the gallbladder such as the absence of a submucosal layer and close proximity to the liver and the hepatoduodenal ligament can encourage progression and spread of the lethal disease [3, 4]. Curative surgical resection (R0) is the only treatment approach that can provide long-term survival, and procedures vary depending on the extent of the tumor spread [5]. Some studies

\footnotetext{
* Correspondence: dichikawa@yamanashi.ac.jp

First Department of Surgery, Faculty of Medicine, University of Yamanashi, 1110 Shimokato, Chuo, Yamanashi 409-3898, Japan
}

recommend radical cholecystectomy with extrahepatic bile duct (EHBD) resection in patients with gallbladder cancer even in the absence of direct invasion to the hepatoduodenal ligament based on studies showing that gallbladder cancer cells frequently spread to the tissues surrounding the EHBD via perineural and lymphatic routes $[6,7]$. In fact, the dense neural network comprising nerve fibers and plexuses circumvolutes EHBD. Furthermore, there is abundant nerve tissue surrounding the gallbladder and the bile duct [8]. Tumor cells can also spread through the perineural space. Importantly, perineural invasion (PNI) was reported as a significant prognostic factor in patients with gallbladder cancer $[6,9]$.

At our institution, as a principle, we have been performing radical cholecystectomy with EHBD resection in

(c) The Author(s). 2019 Open Access This article is distributed under the terms of the Creative Commons Attribution 4.0 International License (http://creativecommons.org/licenses/by/4.0/), which permits unrestricted use, distribution, and 
patients with gallbladder cancer except for those patients with mucosal cancer. In the current study, we assessed correlations between PNI and clinicopathological factors in patients with gallbladder cancer who underwent surgical resection with or without EHBD resection and elucidated the indications for EHBD resection with a focus on the clinical significance of PNI.

\section{Methods}

\section{Patients}

Between 2001 and 2017, 68 patients with gallbladder cancer underwent surgical resection at the University of Yamanashi Hospital. Patients who underwent non-curative resection were excluded from the study. Thus, 50 patients who underwent surgery were included in this retrospective study. We diagnosed all cases as gallbladder cancer using computed tomography (CT), magnetic resonance imaging (MRI), and endoscopic ultrasound (EUS) before surgery; therefore, there was no incidental cancer. None of the patients received preoperative chemotherapy or chemoradiotherapy. In principle, cholecystectomy with EHBD resection was performed in patients with gallbladder cancer except for those patients with mucosal cancer. The clinicopathological features of the cases were reviewed based on data recorded in the hospital database. Tumor specimens and resected lymph nodes were obtained at the time of surgery, fixed immediately in 10\% neutral-buffered formalin, and embedded in paraffin. Macroscopic and microscopic classification of gallbladder cancer was based on the Union for International Cancer Control classification, 7th edition. Complications were defined using the Clavien classification, and grade $\geq 2$ complications were recorded [10]. Tumors invading the neck or the cystic duct of the gallbladder were defined as proximal-type, and those localized in the body or the fundus were defined as distal-type. Circumferential tumor locations were categorized as hepatic and nonhepatic, and circumferential involvement was recorded as hepatic.

Postoperative follow-up comprised evaluation of hematological parameters, computed tomography, and ultrasonography. Follow-up procedures were performed every 3 months for at least 2 years and subsequently continued periodically for at least 5 years. The study was approved by the Ethics Committee of the Yamanashi University and performed in accordance with the ethical standards of the Declaration of Helsinki and its later amendments.

\section{Statistical analysis}

Comparisons between two groups were made using the Student's $t$ test. Associations between PNI and categorical variables were evaluated using the $\chi^{2}$ test. Survival curves were constructed using the Kaplan-Meier method and compared using the log-rank test. Multivariate analyses of prognostic factors related to survival were performed using the Cox proportional hazards test. Statistical significance was set at a $p<0.05$. All statistical analyses were performed with EZR (Saitama Medical Center, Jichi Medical University, Saitama, Japan), a graphical user interface

Table 1 Clinicopathological characteristics of the 50 gallbladder cancer patients

\begin{tabular}{|c|c|}
\hline Characteristics & Number of patients (\%) \\
\hline \multicolumn{2}{|l|}{ Age (years) } \\
\hline$<70$ & $23(46.0)$ \\
\hline $70 \leqq$ & $27(54.0)$ \\
\hline \multicolumn{2}{|l|}{ Gender } \\
\hline Male & $17(34.0)$ \\
\hline Female & $33(66.0)$ \\
\hline \multicolumn{2}{|l|}{ Size $(m m)$} \\
\hline$<35$ & $26(52.0)$ \\
\hline $35 \leqq$ & $24(48.0)$ \\
\hline \multicolumn{2}{|c|}{ Circumferential tumor location } \\
\hline Hepatic side & $32(64.0)$ \\
\hline No hepatic side & $18(36.0)$ \\
\hline \multicolumn{2}{|l|}{ Tumor location } \\
\hline Proximal & $20(40.0)$ \\
\hline Distal & $30(60.0)$ \\
\hline \multicolumn{2}{|l|}{ Surgical approach } \\
\hline EHBD resection (-) & $19(38.0)$ \\
\hline EHBD resection $(+)$ & $31(62.0)$ \\
\hline \multicolumn{2}{|c|}{ Postoperative complications } \\
\hline No & $46(92.0)$ \\
\hline Yes & $4(8.0)$ \\
\hline \multicolumn{2}{|c|}{ Postoperative chemotherapy } \\
\hline No & $31(62.0)$ \\
\hline Yes & $19(38.0)$ \\
\hline \multicolumn{2}{|l|}{ Liver resection } \\
\hline No & $20(40.0)$ \\
\hline Yes & $30(60.0)$ \\
\hline \multicolumn{2}{|l|}{ T category } \\
\hline $\mathrm{T} 1$ & $14(28.0)$ \\
\hline $\mathrm{T} 2$ & $29(58.0)$ \\
\hline T3 & $7(14.0)$ \\
\hline \multicolumn{2}{|l|}{$\mathrm{N}$ category } \\
\hline$N(-)$ & $37(74.0)$ \\
\hline$N(+)$ & $13(26.0)$ \\
\hline \multicolumn{2}{|l|}{ Perineural invasion } \\
\hline No & $37(74.0)$ \\
\hline Yes & $13(26.0)$ \\
\hline
\end{tabular}

EHBD extrahepatic bile duct 
for $\mathrm{R}$ (The $\mathrm{R}$ Foundation for Statistical Computing, Vienna, Austria) [11].

\section{Results}

The relationship of PNI with clinicopathological factors in patients with gallbladder cancer

The clinicopathological characteristics of the patients included in the present study are summarized in Table 1 . PNI adjacent to the tumor lesion was detected in 13 of the 50 cases $(26.0 \%)$. Representative photomicrographic images of PNI are shown in Fig. 1. PNI was correlated significantly with male sex $(p=0.021)$, presence of postoperative chemotherapy $(p<0.001)$, presence of postoperative complications $(p=0.049)$, proximal-type tumor $(p=0.003)$, lymphatic invasion $(p=0.003)$, vascular invasion $(p<0.001)$, and advanced T stage $(p=0.010)$. PNI was not detected in patients with stage T1 cancer. PNI did not correlate with other clinicopathological factors such as $\mathrm{N}$ stage, numbers of resected lymph nodes, and lymph node ratio (Table 2).

\section{The prognostic impact of $\mathrm{HH}$}

The median follow-up period of the study cohort was 63 months. Figure 2 shows the survival curves stratified according to the PNI status. Briefly, the overall and disease-free survival rates were significantly lower in the PNI-positive patients compared with the PNI-negative patients $(p<0.005$ and $p<0.001$, respectively).

Univariate analysis identified lymphatic and vascular invasion as well as the $\mathrm{N}$ stage as significant prognostic factors, whereas age, sex, tumor size, tumor location, EHBD resection, and the $\mathrm{T}$ stage were not found to be significantly associated with prognosis (Table 3 ).
Subsequent multivariate analysis demonstrated that the presence of PNI was an independent prognostic factor $(p<0.001)$, as were lymphatic invasion $(p=0.007)$ and $\mathrm{N}$ stage $(p<0.001)$ (Table 3$)$.

In this series, PNI was found in only three of the 30 cases with distal-type gallbladder cancer; all three patients were treated by cholecystectomy with EHBD resection. However, all patients developed various types of recurrences even after R0 resection; therefore, the extended procedures were found not to have clinical therapeutic efficacy in these patients.

\section{Discussion}

Malignant tumors develop and progress via various routes of spread including hematogenous and lymphatic dissemination and local invasion. Local invasion is generally divided into direct invasion with destruction of the existing tissues and tumor spread through the loose space with particular histologic nature. As a representative of the latter, spreading through perineural space, i.e., PNI, is widely recognized as an important adverse pathological feature of many malignancies including pancreatic, prostate, and neck cancers $[12,13]$. In these cancer types, the presence of PNI is a well-known poor prognostic factor $[12,13]$. Similarly, PNI is detected frequently in gallbladder cancer and acknowledged for its clinical significance $[6,9]$.

PNI was detected more frequently in hepatic-sided and proximal-type gallbladder cancer in the current study cohort. Furthermore, PNI was an independent prognostic factor. However, our analysis indicated that PNI was not correlated with lymph node metastasis although lymphatic vessels and lymph nodes are

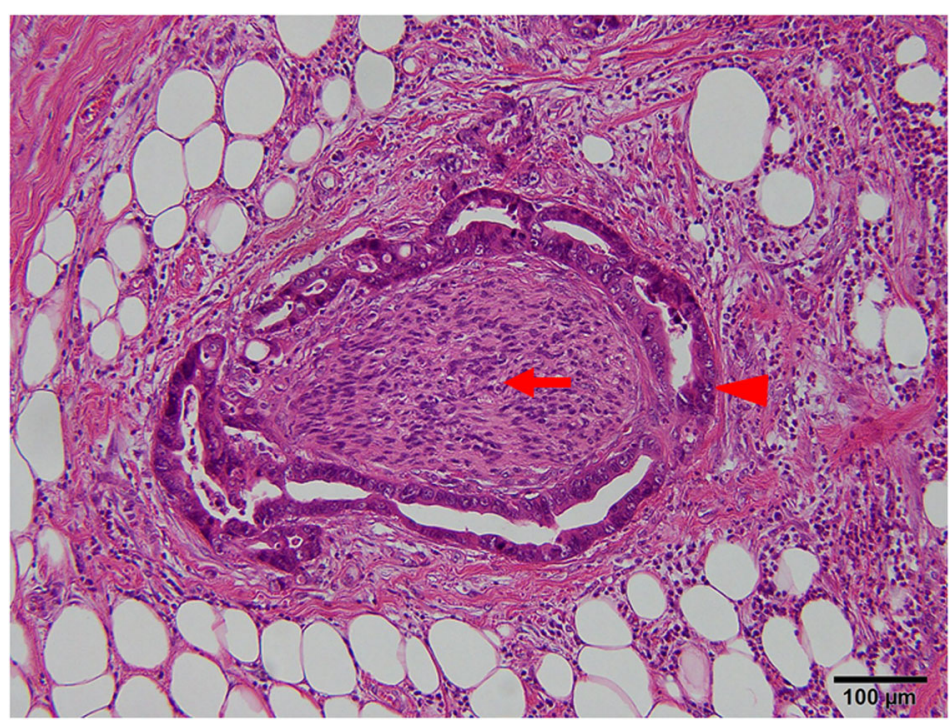

Fig. 1 Representative photomicrographs of perineural invasion adjacent to tumor lesion; arrowhead indicates tumor and arrow indicates nerve 
Table 2 Relationships between perineural invasion and clinicopathologic factors of gallbladder cancer patients

\begin{tabular}{|c|c|c|c|}
\hline \multirow[t]{2}{*}{ Characteristics } & \multirow{2}{*}{$\begin{array}{l}\text { PNI (-) } \\
n=37(74.0 \%)\end{array}$} & \multirow{2}{*}{$\begin{array}{l}\mathrm{PNI}(+) \\
n=13(26.0 \%)\end{array}$} & \multirow[t]{2}{*}{$p$ value } \\
\hline & & & \\
\hline \multicolumn{4}{|l|}{ Age (years) } \\
\hline$<70$ & $15(40.5)$ & $8(61.5)$ & \multirow[t]{2}{*}{0.215} \\
\hline $70 \leqq$ & $22(59.5)$ & $5(38.5)$ & \\
\hline \multicolumn{4}{|l|}{ Gender } \\
\hline Male & $9(23.4)$ & $8(61.5)$ & \multirow[t]{2}{*}{$0.021^{*}$} \\
\hline Female & $28(75.7)$ & $5(38.5)$ & \\
\hline \multicolumn{4}{|l|}{ Postoperative chemotherapy } \\
\hline No & $29(78.4)$ & $2(15.4)$ & \multirow[t]{2}{*}{$<0.001^{*}$} \\
\hline Yes & $8(21.6)$ & $11(84.6)$ & \\
\hline \multicolumn{4}{|l|}{ Postoperative complications } \\
\hline No & $36(97.3)$ & $10(76.9)$ & \multirow[t]{2}{*}{$0.049^{*}$} \\
\hline Yes & $1(2.7)$ & $3(23.1)$ & \\
\hline \multicolumn{4}{|l|}{ Size (mm) } \\
\hline$<35$ & $20(54.1)$ & $6(46.2)$ & \multirow[t]{2}{*}{0.751} \\
\hline $35 \leqq$ & $17(45.9)$ & $7(53.8)$ & \\
\hline \multicolumn{4}{|l|}{ Circumferential tumor location } \\
\hline Hepatic side & $21(56.8)$ & $11(84.6)$ & \multirow[t]{2}{*}{0.098} \\
\hline No hepatic side & $16(43.2)$ & $2(15.4)$ & \\
\hline \multicolumn{4}{|l|}{ Tumor location } \\
\hline Proximal & $10(27.0)$ & $10(76.9)$ & \multirow[t]{2}{*}{$0.003^{*}$} \\
\hline Distal & $27(73.0)$ & $3(23.1)$ & \\
\hline \multicolumn{4}{|l|}{ Lymphatic invasion } \\
\hline No & $27(73.0)$ & $3(23.1)$ & \multirow[t]{2}{*}{$0.003^{*}$} \\
\hline Yes & $10(27.0)$ & $10(76.9)$ & \\
\hline \multicolumn{4}{|l|}{ Vascular invasion } \\
\hline No & $32(86.5)$ & $3(23.1)$ & \multirow[t]{2}{*}{$<0.001^{*}$} \\
\hline Yes & $5(13.5)$ & $10(76.9)$ & \\
\hline \multicolumn{4}{|l|}{ T category } \\
\hline $\mathrm{T} 1$ & $14(37.8)$ & $0(0.0)$ & \multirow[t]{2}{*}{$0.010^{*}$} \\
\hline $\mathrm{T} 2, \mathrm{~T} 3$ & $23(62.2)$ & $13(100.0)$ & \\
\hline \multicolumn{4}{|l|}{ N category } \\
\hline N (-) & $29(78.4)$ & $8(61.5)$ & \multirow[t]{2}{*}{0.281} \\
\hline$N(+)$ & $8(21.6)$ & $5(38.5)$ & \\
\hline Number of resected lymph nodes & 6.32 & 5.00 & 0.494 \\
\hline Lymph node ratio & 0.24 & 0.21 & 0.791 \\
\hline
\end{tabular}

$P N /$ perineural invasion. Significant differences between samples are indicated as ${ }^{*} p<0.05$

adjacent to the nerves and plexuses around the gallbladder and the EHBD. Results from several recent experimental studies suggested that tumor cells might have increased affinity for nerve [14], implicating PNI in arising from a reciprocal interaction between the tumor cells and the microenvironment of the host nerve. The mechanisms of progression through nerve fibers and the lymphatic route might be distinct. To support this possibility, there was no significant correlation between PNI and specific recurrence patterns such as lymphatic or local recurrence in the current study cohort (data not shown).

Whether EHBD resection should be routinely performed in patients with gallbladder cancer remains 


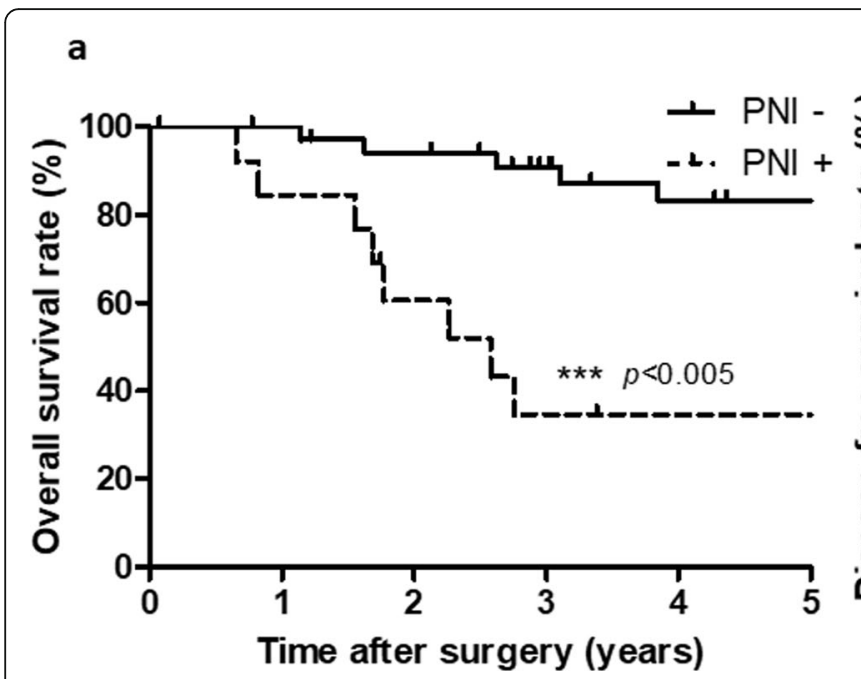

b

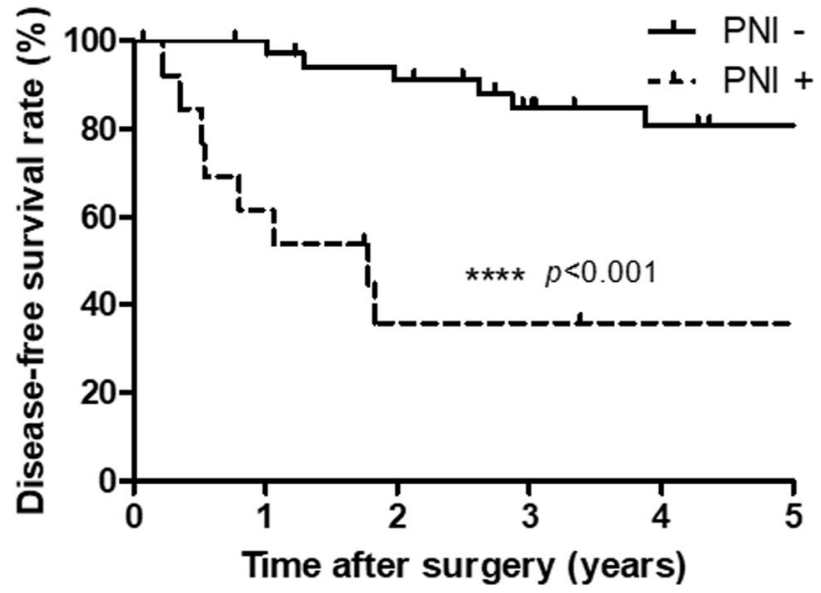

Fig. 2 Kaplan-Meier curves for a overall survival rates and $\mathbf{b}$ disease-free survival rates. ${ }^{* *} p<0.005$ compared with PNI $(-)$ group using the logrank test. ${ }^{* * *} p<0.001$ compared with PNI (-) group using the log-rank test. PNI perineural invasion

controversial [5]. Some studies suggested that EHBD resection should be performed routinely during radical cholecystectomy $[6,15,16]$, whereas others reported that EHBD resection did not improve prognosis [17-19]. D' Angelica et al. suggested EHBD resection is appropriate when necessary to clear disease but are not mandatory in all cases [20]. We agree with this report. Moreover, they have reported that the median number of lymph nodes was similar regardless of whether EHBD resection had been performed, and lymphadenectomy plus EHBD resection was not associated with an improvement in survival $[17,20]$. Therefore, routine EHBD resection was not associated with lymph node yield or survival. Recently, Kurahara et al. found that EHBD resection improved prognosis in patients with proximal-type gallbladder cancer [21].

Considering that EHBD resection in combination with cholecystectomy is recognized as extended wide resection for cases with spread through PNI, EHBD resection is not necessary for patients with stage T1 gallbladder cancer with no evidence of PNI. Conversely, PNI was rarely detected in distal-type gallbladder cancers. The lower frequency of PNI in distal-type tumors might be due to the sparse nerve networks in the distal lesion or might reflect a biological feature. Intraoperative pathological diagnosis for the proximal margin should be useful for the decision for performing EHBD resection. However, PNI cannot be diagnosed before surgery. Therefore, it is important to know that PNI is detected more frequently in proximal-type gallbladder cancer and rarely detected in distal-type cancer.

All patients with PNI-positive distal-type gallbladder cancer developed recurrence despite the EHBD resection. In this study, there were no cases of R1 resection for not performing EHBD; however, two cases with PNI-positive distal-type gallbladder cancer were R1 resection despite performing EHBD resection (data not shown). These results indicate that EHBD resection in combination with cholecystectomy failed to provide prognostic benefit for those with distal-type gallbladder cancer. However, the number of distal-type gallbladder cancer was small in this study, and further studies are warranted to confirm that. If patients with PNI-positive distal-type gallbladder cancer obtain long-term prognosis by performing EHBD resection, EHBD resection should be performed even for patients with distal-type cancer.

To the best of our knowledge, no studies to date evaluated the clinical significance of EHBD resection for gallbladder cancer in the context of PNI. Magnon et al. demonstrated that surgical sympathectomy prevented the early-phase prostate cancer development [22], whereas Zhao et al. demonstrated that surgical denervation of the stomach markedly reduced gastric tumor incidence and progression [23]. Total resection of the nerve tissues around the EHBD should be discussed in two aspects: survival benefit with total removal of the tumor cells around the nerve tissues and potential post-denervation effects on tumor development and progression. The current study demonstrated that EHBD resection in combination with cholecystectomy may not provide any overt survival benefits at least for certain subsets of patients with gallbladder cancer. However, this study has certain limitations. The number of cases analyzed was small, and multi-center large-scale investigations are necessary to confirm these results. 
Table 3 Univariate and multivariate disease-free survival analyses of prognostic factors

\begin{tabular}{|c|c|c|c|c|}
\hline \multirow[b]{2}{*}{ Characteristics } & \multicolumn{2}{|l|}{ Univariate } & \multicolumn{2}{|l|}{ Multivariate } \\
\hline & $p$ value & Hazard ratio & $95 \% \mathrm{Cl}$ & $p$ value \\
\hline \multicolumn{5}{|l|}{ Age years } \\
\hline$<65$ & 0.410 & & & NA \\
\hline \multicolumn{5}{|l|}{$65 \leqq$} \\
\hline \multicolumn{5}{|l|}{ Gender } \\
\hline Male & 0.114 & & & NA \\
\hline \multicolumn{5}{|l|}{ Female } \\
\hline \multicolumn{5}{|l|}{ Size $(m m)$} \\
\hline$<35$ & 0.433 & & & NA \\
\hline \multicolumn{5}{|l|}{$35 \leqq$} \\
\hline \multicolumn{5}{|c|}{ Circumferential tumor location } \\
\hline Hepatic side & 0.073 & & & NA \\
\hline \multicolumn{5}{|c|}{ No hepatic side } \\
\hline \multicolumn{5}{|l|}{ Tumor location } \\
\hline Proximal & 0.500 & & & NA \\
\hline \multicolumn{5}{|l|}{ Distal } \\
\hline \multicolumn{5}{|l|}{ EHBD resection } \\
\hline No & 0.352 & & & NA \\
\hline \multicolumn{5}{|l|}{ Yes } \\
\hline \multicolumn{5}{|l|}{ Liver resection } \\
\hline No & 0.706 & & & NA \\
\hline \multicolumn{5}{|l|}{ Yes } \\
\hline \multicolumn{5}{|c|}{ Lymphatic invasion } \\
\hline No & 0.056 & & & NA \\
\hline \multicolumn{5}{|l|}{ Yes } \\
\hline \multicolumn{5}{|l|}{ Vascular invasion } \\
\hline No & $0.018^{*}$ & 1 & & \\
\hline Yes & & 1.465 & $0.201-3.015$ & 0.717 \\
\hline \multicolumn{5}{|l|}{ T category } \\
\hline $\mathrm{T} 1$ & 0.177 & & & \\
\hline $\mathrm{T} 2, \mathrm{~T} 3$ & & & & NA \\
\hline \multicolumn{5}{|l|}{ N category } \\
\hline$N(-)$ & $<0.001^{*}$ & 1 & & \\
\hline$N(+)$ & & 13.24 & $3.759-46.64$ & $<0.001^{*}$ \\
\hline \multicolumn{5}{|c|}{ Perineural invasion } \\
\hline No & $<0.001^{*}$ & 1 & & \\
\hline Yes & & 11.96 & $2.594-55.14$ & $<0.001^{*}$ \\
\hline
\end{tabular}

$\overline{E H B D}$, extrahepatic bile duct; $C l$, confidence interval; $N A$, not adopted. Significant differences between samples are indicated as ${ }^{*} p<0.05$

\section{Conclusions}

In conclusion, the current study clearly demonstrated the prognostic impact of PNI in patients with gallbladder cancer. We suggest that EHBD resection in combination with cholecystectomy may not be useful at least in patients with stage $\mathrm{T} 1$ disease and distal-type tumors from a perspective of PNI.
Abbreviations

EHBD: Extrahepatic bile duct; PNI: Perineural invasion

\section{Acknowledgements}

The authors are grateful to Makiko Mishina for expert technical assistance.

\section{Authors' contributions}

MS performed the majority of experiments and drafted the manuscript; $\mathrm{KH}, \mathrm{HN}$, $\mathrm{AH}$, and $\mathrm{KH}$ performed acquisition of data; $\mathrm{SR}, \mathrm{SH}, \mathrm{FS}, \mathrm{AH}, \mathrm{KY}, \mathrm{SM}$, and IS 
performed analysis and interpretation of data. ID designed the study and helped to draft the manuscript. All authors have revised and approved the manuscript.

\section{Funding}

No external funding was used for conducting this study.

\section{Availability of data and materials}

Data were collected at University of Yamanashi and are not publicly available.

\section{Ethics approval and consent to participate}

The study was approved by the Ethics Committee of the Yamanashi University and performed in accordance with the ethical standards of the Declaration of Helsinki and its later amendments.

\section{Consent for publication}

All study participants provided informed written consent prior to their study enrollment.

\section{Competing interests}

The authors declare that they have no competing interests.

Received: 30 August 2019 Accepted: 29 October 2019

Published online: 30 November 2019

\section{References}

1. Wilkinson DS. Carcinoma of the gall-bladder: an experience and review of the literature. The Australian and New Zealand journal of surgery. 1995; 65(10):724-7.

2. Lim H, Seo DW, Park DH, Lee SS, Lee SK, Kim MH, Hwang S. Prognostic factors in patients with gallbladder cancer after surgical resection: analysis of 279 operated patients. Journal of clinical gastroenterology. 2013;47(5):443-8.

3. Shih SP, Schulick RD, Cameron JL, Lillemoe KD, Pitt HA, Choti MA, Campbell KA, Yeo CJ, Talamini MA. Gallbladder cancer: the role of laparoscopy and radical resection. Annals of surgery. 2007:245(6):893-901.

4. Ebata T, Ercolani G, Alvaro D, Ribero D, Di Tommaso L, Valle JW. Current status on cholangiocarcinoma and gallbladder cancer. Liver cancer. 2016; 6(1):59-65.

5. Hueman MT, Vollmer CM Jr, Pawlik TM. Evolving treatment strategies for gallbladder cancer. Ann Surg Oncol. 2009;16(8):2101-15.

6. Lee H, Choi DW, Park JY, Youn S, Kwon W, Heo JS, Choi SH, Jang KT Surgical strategy for T2 gallbladder cancer according to tumor location. Ann Surg Oncol. 2015;22(8):2779-86

7. Jung W, Jang JY, Kang MJ, Chang YR, Shin YC, Chang J, Kim SW. Effects of surgical methods and tumor location on survival and recurrence patterns after curative resection in patients with T2 gallbladder cancer. Gut Liver. 2016;10(1):140-6.

8. Jensen KJ, Alpini G, Glaser S. Hepatic nervous system and neurobiology of the liver. Comprehensive Physiology. 2013;3(2):655-65.

9. Suzuki S, Yokoi Y, Kurachi K, Inaba K, Ota S, Azuma M, Konno H, Baba S, Nakamura S. Appraisal of surgical treatment for pT2 gallbladder carcinomas. World journal of surgery. 2004;28(2):160-5.

10. Clavien PA, Barkun J, de Oliveira ML, Vauthey JN, Dindo D, Schulick RD, de Santibanes E, Pekolj J, Slankamenac K, Bassi C, et al. The Clavien-Dindo classification of surgical complications: five-year experience. Annals of surgery. 2009;250(2):187-96.

11. Kanda Y. Investigation of the freely available easy-to-use software 'EZR' for medical statistics. Bone marrow transplantation. 2013;48(3):452-8.

12. Soo KC, Carter RL, O'Brien CJ, Barr L, Bliss JM, Shaw HJ. Prognostic implications of perineural spread in squamous carcinomas of the head and neck. The Laryngoscope. 1986;96(10):1145-8.

13. Takahashi T, Ishikura H, Motohara T, Okushiba S, Dohke M, Katoh H. Perineural invasion by ductal adenocarcinoma of the pancreas. Journal of surgical oncology. 1997;65(3):164-70.

14. Bakst RL, Wong RJ. Mechanisms of perineural invasion. J Neurological Surg Part B Skull Base 2016:77(2):96-106.

15. Shimizu Y, Ohtsuka M, Ito H, Kimura F, Shimizu H, Togawa A, Yoshidome H, Kato A, Miyazaki M. Should the extrahepatic bile duct be resected for locally advanced gallbladder cancer? Surgery. 2004;136(5):1012-7 discussion 1018.
16. Pandey D, Garg PK, Manjunath NM, Sharma J. Extra-hepatic bile duct resection: an insight in the management of gallbladder cancer. Journal of gastrointestinal cancer. 2015;46(3):291-6.

17. Kosuge T, Sano K, Shimada K, Yamamoto J, Yamasaki S, Makuuchi M. Should the bile duct be preserved or removed in radical surgery for gallbladder cancer? Hepato-gastroenterology. 1999:46(28):2133-7.

18. Araida T, Higuchi R, Hamano M, Kodera Y, Takeshita N, Ota T, Yoshikawa T, Yamamoto M, Takasaki K. Should the extrahepatic bile duct be resected or preserved in R0 radical surgery for advanced gallbladder carcinoma? Results of a Japanese Society of Biliary Surgery Survey: a multicenter study. Surgery today. 2009:39(9):770-9.

19. Chen C, Geng Z, Shen H, Song H, Zhao Y, Zhang G, Li W, Ma L, Wang L. Long-term outcomes and prognostic factors in advanced gallbladder cancer: focus on the advanced T stage. PloS one. 2016;11(11):e0166361.

20. D'Angelica M, Dalal KM, DeMatteo RP, Fong Y, Blumgart LH, Jarnagin WR. Analysis of the extent of resection for adenocarcinoma of the gallbladder. Ann Surg Oncol. 2009:16(4):806-16.

21. Kurahara H, Maemura K, Mataki Y, Sakoda M, lino S, Kawasaki Y, Mori S, Arigami T, Kijima Y, Shinchi H, et al. Indication of extrahepatic bile duct resection for gallbladder cancer. Langenbeck's Archives Surg. 2018;403(1):45-51.

22. Magnon C, Hall SJ, Lin J, Xue X, Gerber L, Freedland SJ, Frenette PS. Autonomic nerve development contributes to prostate cancer progression. Science (New York, NY). 2013;341(6142):1236361.

23. Zhao CM, Hayakawa Y, Kodama Y, Muthupalani S, Westphalen CB, Andersen GT, Flatberg A, Johannessen H, Friedman RA, Renz BW, et al. Denervation suppresses gastric tumorigenesis. Sci Transl Med. 2014;6(250):250ra115.

\section{Publisher's Note}

Springer Nature remains neutral with regard to jurisdictional claims in published maps and institutional affiliations.

Ready to submit your research? Choose BMC and benefit from:

- fast, convenient online submission

- thorough peer review by experienced researchers in your field

- rapid publication on acceptance

- support for research data, including large and complex data types

- gold Open Access which fosters wider collaboration and increased citations

- maximum visibility for your research: over $100 \mathrm{M}$ website views per year

At BMC, research is always in progress.

Learn more biomedcentral.com/submission 